\title{
Discussion on the development strategy of travel agency under the impact of tourism e-commerce
}

\author{
Luo Jing ${ }^{1}$ \\ ${ }^{1}$ Tourism Management College of Business, Xi'an International University, Xi’an, Shaanxi, China, 710077
}

Keywords: tourism e-commerce; travel agency development; strategy analysis

\begin{abstract}
The emergence and development of the Internet has brought new impacts on e-commerce, prompting the traditional travel agencies to constantly change their own development model, and actively respond to the requirements of the new era of development. Based on this, this paper analyzes the development strategy of travel agency under the impact of tourism e-commerce, hoping to provide reference for the better development of travel agencies.

The development of the Internet has promoted the development and progress of society in a certain way, bringing more convenient and fast life style to people, and meanwhile, it has a certain impact on many traditional industries. The tourism industry is one of the industries affected by it. The development of tourism business to the traditional travel patterns change, many people no longer need to travel through to achieve the purpose of tourism, it only needs information through the network, can detailed planning tourist routes, achieve good effect of tourism. Even many other services provided by the electricity supplier have become important assistance for people to facilitate tourism. The traditional travel agencies to electricity suppliers in the development of competition in the era of a better, must be combined with their own situation of continuous improvement and development, so that it can compete with the tourism business, and access to sustainable development[1].
\end{abstract}

\section{The traditional travel agency e-commerce development}

The development of science and technology makes Internet become one of the essential tools in people's lives, which not only bring very convenient way of life, is to let people travel more convenient and simple. It is also because of this, the development of the electricity supplier brought a strong impact on the traditional travel agencies, traditional travel agencies in the development of electronic commerce has also given a further exploration and research, the development of the status quo mainly include the following aspects.

Traditional travel agencies face electricity supplier "threat" to actively expand the construction site, regardless of traditional country prefix, prefix in the travel agency, especially recently with strong capital travel agencies have established their website system, and has invested huge funds. But the travel agency belongs to the category of light asset type enterprise, the capital cost of the website construction has already far exceeded its imagination category, but it is difficult to compare with the investment of the electricity supplier[2].

The website operation aspect, the traveling electricity supplier commercial website's operation, is by a group of skilled specialized personnel in the operation, its both in the website management or adapts the market adjustment aspect to have the specialty. For the traditional travel agencies, hire a number of people who understand the network technology costs relatively high, enterprises in the financial support of the existence of relatively large difficulty. Because of the restriction of funds and talents, it is very difficult for the traditional travel agency to develop e-commerce.

Travel agency network management, the more inclined to the traditional management mode, there is a big increase in space in network management, network management system is not only specific, but there are some flaws in the network update, follow up and so on, it is difficult to meet the needs of customers or the real traveler. This makes it have the tendency to exist in name only in the website construction, and it is difficult to achieve the goal of promoting its own development 
through the form of the network[3].

\section{The impact of e-commerce on traditional travel agencies}

The travel agency belongs to the service sector, also belongs to the scope of the information industry, travel agency sales to provide tourists with tourism related information for tourism management considering the travel agency is a multinational or trans regional, the tourism information sharing degree put forward higher requirements. Travel information in the Internet era is highly centralized state in tourism information search is very convenient, the tourists can easily find tourist attractions, hotels, tourist traffic and other information, for some potential customers, to understand the relevant information of interest rates, only need to enter the relevant website to fully break the limits autoimmune factors[4].

The travel agency can be their own products, presented to the customers through the combination of various industries, is closely related with the tourist products, most travel agents will be lower than the market price, make the integration process related to buy products, added to its service to the project, the travel agency will naturally become the tourism industry agents, to obtain the corresponding reward. With the advent of tourism e-commerce, the agency advantages of travel agents are also facing unprecedented challenges. In addition, for e-commerce, the cost is almost zero, and the travel agency is even greater demand in the Commission, which is the key point of the impact of e-commerce, but also to travel agency functions should be weakened.

In the era of network information, the choice of consumers is diverse, and the network competition becomes more and more fierce. At present, the development of travel website tends to mature stage, which will provide more clear information to users, and provide a very simple operation, provides many convenient services for the majority of Internet users. However, there are fierce competition between tourism websites. In the fierce competition, more and more tourist electricity providers provide more value-added services for tourists, which has become another highlight of attracting consumers. While the traditional travel agencies in value-added services is in a weak position, it has become part of the impact of the electricity supplier.

\section{The development strategy of travel agency under the impact of tourism e-commerce}

Tourism e-commerce is now emerging, and is not to replace the travel agency, but to the Internet and tourism together, will travel as a middleman role fully reflected, skilful use of business knowledge and skills to join the network, in order to carry out electronic commerce. With the development of electronic commerce, the office has become a real change in the network platform, through the development of the virtual business "- where the" virtual business "refers to the transmission and processing of information from post earnings information earnings change.

As a travel agency, should continue to increase efforts to expand services, closely around the market to expand, adhere to customer demand oriented concept, to ensure that different customers travel can be satisfied, should proceed from the following aspects: first, to carry out activities in the process of daily management, should focus on strengthening its transparency, especially customer the highest degree of concern of the charges. In the site in the browsing process, according to the customer's requirement, in the process of planning of tourist routes, should be based on the customer's consumption ability to design, to ensure to provide the best travel route for customers. Second, after the completion of the construction of travel agency network platform, network platform service function should constantly improve, should respond to the consultation of customers in the first time, in the process of relevant fees charged in the safety of both should be guaranteed, to ensure high efficiency and high accuracy, high level of service customer. Third, the travel agency can to construct the network of its attractions, on our platform, adding their own product related attractions and willing to cooperate with the travel agency, to join the travel agency, to collect relevant fees. For customers, can avoid the cumbersome online search link, provide much convenience for it, for travel agents, will be able to sell their products at the same time, the amount of its own information platform becomes more abundant. 
At this stage, China's tourism websites emerge in an endless stream, and its hierarchical division is also very different, in order to emerge in many sites, it should have its own characteristics, focusing on the promotion of the core competitiveness of travel agencies. As a service industry, whether it is service content, service scope, or service quality, should be made to develop and continue to make breakthroughs, and constantly improve their own gold content. Today, many travel websites are difficult to clear the direction of their service, only a small amount of services provided to customers, for customers to meet the demand, there are many difficulties in production and business aspects of the effect of marginal effect. As a tourism website, only with good quality can the optimization be developed, the authenticity and universality of the information can be guaranteed. The core competitiveness of the website and traditional resources are inseparable, should continue to innovate the traditional resources, make the tourism website to maintain the vitality of tourism services to ensure good development of electronic commerce for their continuous development, so as to avoid the occurrence of the bubble economy, in the process of development, avoid superstition and conservative, should adhere to the principle of seeking truth from facts and the implementation of market access the bold exploration, only in this way, in the fierce market competition, in order to achieve tourism website development, website to travel convenience service to more customers[5].

The Internet is an open network resource sharing, and in a state of anarchy, can see the information on the Internet visitors, intranet is corresponding to the Internet, intranet is LAN, built in between the head office and branch and cooperative units. In terms of information, internal members can achieve a high degree of sharing, which is the condensed internet. Some enterprises have very high requirements for information, should conscientiously carry out the relevant work within the enterprise network, through this model, provide more convenience for the flow of information, to avoid information loss situation. Because of the complicated and complicated tourist information, there are many difficulties in finding useful information. Using this model can help solve such problems and improve the efficiency of work. Cooperation between the part of the travel agency is very close, this kind of travel agency on Intranet was established, through the use of Intranet, help to increase the economic efficiency of enterprises, through information sharing level, can carry out cooperation between travel agencies, make full use of its resources, provide convenience for expanding the scale and scope of the travel agency business to establish a stable, long-term relationship between them. The normal operation of the intranet, cannot do without safety protection, shall strictly examine into members, have common interests only allow enterprises to enter the internal members if there is a problem, will have a direct impact on the development of enterprises, have incalculable consequences[6].

First, in the tourism website design process, not just a simple list of products, should be the pictures and text of the reasonable design, be vivid, can attract people's attention, if the business is too simple and direct, consumers will get tired of them. Should change the content of the site, should be based on changes in market demand, changes in the content of the site. Second, we should ensure the accuracy, specificity and systematicness of the website information. In the relevant content of the website, we should list clearly the tourist routes, text, attractions, pictures and related prices. Third, we should pay attention to the propaganda work of the propaganda commodity website, if it can not attract visitors, then the site is worthless. As a travel agency, with propaganda measures should be fully utilized, through television ads, radio advertising and printing leaflets in the form of publicity for their own website, can send a message to the customer, it can also in some popular travel magazines and websites to promote their own. In order to achieve the attention to enhance.

At present, the tourism market competition is becoming increasingly fierce, in order to occupy a favorable position in the fierce competition in the market, should pay attention to carry out all aspects of the work, for all aspects of the work should attach great importance to pay attention to and carry out the tourist oriented service concept, in all aspects of the work carried out in the process for customer service, service management should not be overlooked don't let down, and earnestly carry out should also attach great importance to it, strengthen customer service service 
management, mainly refers to the evaluation on tourism consumers. As the Internet technology developed in the enterprise, influence, occupy a very important content of network evaluation, has a very strong role, as a travel agency, we should make the quality of tourism products is guaranteed, as the premise, set up specialized staff, responsible for complaints from visitors and make relevant treatment, all aspects of the tourists question, serious, patient and detailed answer, so that visitors enjoy satisfactory service to enterprises in order to enhance the degree of praise. Secondly, the opinions of tourists should be paid attention to. In the follow-up work, we should constantly adjust and optimize, and do a good job in the improvement of the corresponding work. Third, for tourists travel experience, travel agencies also need to be ready to follow up, through after-sales service quality improvement, to achieve consumer satisfaction and recognition[7].

\section{Conclusion}

The development of the tourism business have a great impact for the development of the traditional travel agencies, travel agencies continue to change the traditional business model, the requirements of the new era and standard into the development of the travel agency, through virtual management, enhance the core competitiveness of the website, and the construction of customer service, improve the quality of service and to promote consumers have to travel agency approval and satisfaction. We must see that the development of the tourism business also brought new opportunities for the development of travel agencies, travel agencies also seize the development of the reform era torrent, high utilization of information processing mode, to seek a new path for the development of their own, make their own path of development is more and more broad.

\section{References}

[1] Tian L. Study on the Development of Travel Agencies under the Impact of Tourism Electronic Business[J]. Journal of Jinling Institute of Technology, 2008.

[2] Lalitha K, Paul N I J. " A Study on the Impact of E-Commerce on Retail Marketing in Tourism "[C]// International Seminar on "tourism Sector in India- Development, Sustainability and Challenges. 2015.

[3] Lu Q, Yang Y, Yuksel U. The impact of a new online channel: An empirical study[J]. Annals of Tourism Research, 2015, 54:136-155.

[4] Tsai H T, Huang L, Lin C G. Emerging e-commerce development model for Taiwanese travel agencies[J]. Tourism Management, 2005, 26(5):787-796.

[5] ŢUclea C E, Vasile D C, ŞChiopu A F, et al. Facets of economic and financial crisis impact on strategic planning of travel agencies.[J].Amfiteatru Economic, 2014, 16(Special Issue 8):1222-1237.

[6] Racherla P, Mandviwalla M. Moving from Access to Use of the Information Infrastructure: A Multilevel Sociotechnical Framework[J]. Information Systems Research, 2013, 24(3):709-730.

[7] Jiang J B, Liang F F. A mechanism study on the impact of tourism e-commerce maturity on the e-travel booking intention: as a case with Ctrip.[J]. Tourism Tribune, 2014, 29(2):75-83. 